\title{
Effectiveness and safety of levosulpiride in the treatment of dysmotility-like functional dyspepsia
}

\author{
R Lozano' \\ MG Peralta Concha ${ }^{2}$ \\ A Montealegre ${ }^{3}$ \\ L de Leon ${ }^{3}$ \\ J Ortiz Villalba ${ }^{4}$ \\ HO Lee Esteban ${ }^{5}$ \\ $M$ Cromeyer $^{6}$ \\ JA Rivas García ${ }^{7}$ \\ A Brossa ${ }^{8}$ \\ G Lluberes ${ }^{8}$ \\ E Izquierdo Sandi 9 \\ H Burgos Quirós ${ }^{10}$
}

'Grupo Ferrer Internacional, Avda. Diagonal 549, E-08029, Barcelona, Spain; ${ }^{2}$ Department of

Gastroenterology, Hospital de la Policía Nacional del Perú, Lima, Perú; ${ }^{3}$ Gastroenterology and Internal Medicine, Hospital Chiriquí, David, República de Panamá; ${ }^{4}$ Center of Medical Specialties, Asunción del Paraguay, Paraguay; ${ }^{5}$ Gastroklinik, Guatemala; ${ }^{6} \mathrm{Hospital}$ de Diagnóstico, San Salvador, El Salvador; ${ }^{7}$ Hospital Escuela, Tegucigalpa, Honduras; ${ }^{8}$ Clínica Abreu, Santo Domingo, República de Santo Domingo; ${ }^{9}$ Hospital Dr. Calderón Guardia, San Pedro, San José, Costa Rica; and ${ }^{10} \mathrm{Gastroenterology}$ Clinic, San Juan de Tibás, San José, Costa Rica

Correspondence: R Lozano

Grupo Ferrer Internacional, Avenida Diagonal 549, E-08029 Barcelona, Spain.

Tel: +34 936003794

Fax: +34934907078

Email: rlozano@ferrergrupo.com

\begin{abstract}
The objective of this study was to assess the effectiveness and safety of levosulpiride in patients with dysmotility-like functional dyspepsia including nonerosive reflux esophagitis in conditions of daily practice. The study was conducted as a prospective, open-label, multicenter design in 342 patients with dysmotility-like functional dyspepsia $(n=279)$ and nonerosive reflux disease ( $\mathrm{n}=63$ ), who received levosulpiride $25 \mathrm{mg} 3$ times daily orally for 4 weeks. Individual symptoms (pain/discomfort, fullness, bloating, early satiety, pyrosis, regurgitation, and nausea/vomiting) and a global symptom score were assessed at 15, 30, and 60 days after starting treatment. Adverse events also were recorded. There were 151 men and 191 women (mean age 38.8 years) who referred dyspeptic symptoms for a mean of 10.2 (10.7) months. A total of $66.4 \%$ patients were treated with $75 \mathrm{mg}$ /day levosulpiride and $33.6 \%$ with $50 \mathrm{mg}$ /day. At the 15-day visit, a decrease greater than $50 \%$ in the global symptom score was observed. The frequency and intensity of individual symptoms showed a statistically significant decrease $(\mathrm{p}<0.001)$ at all visits compared with baseline. At the 30 -day visit, all symptoms had almost disappeared, a trend that was maintained until the last visit. Treatment with levosulpiride was well tolerated and only 40 adverse events were recorded (galactorrhea $26.7 \%$, somnolence $17.8 \%$, fatigue $11.1 \%$, headache $11.5 \%$ ) and no patient had to abandon the study due to side effects. In conclusion, levosulpiride is an effective and safe drug in the treatment of dysmotility-like functional dyspepsia and non-erosive reflux disease.
\end{abstract}

Keywords: (MeSH terms): sulpiride/administration \& dosage, dyspepsia/drug therapy, levosulpiride, sulpiride/analogs \& derivatives, administration oral, adult

\section{Introduction}

A common challenge in primary care is how best to evaluate and treat patients with dyspepsia. Dyspepsia accounts for a relevant workload for general practitioners (Heikkinen et al 1996; Van Bommel et al 2001; Maconi et al 2002). Results of different studies have shown that the proportion of patients with dyspepsia who consulted their general practitioner varied widely from 3\% to 45\% (Jones and Lydeard 1989; Bodger et al 2000) among the eight doctors who participated in a prevalence study of dyspepsia (Jones and Lydeard 1989). In population-based surveys carried out in England, an overall six month prevalence of dyspepsia of $38 \%$ has been reported (Jones and Lydeard 1992). In a study carried out in Denmark, the annual incidence rate of dyspepsia was 3.4\% (Meineche-Schmidt and Krag 1998), but in a random Mediterranean population, the prevalence of dyspepsia was $24 \%$ (Caballero Plasencia et al 2000).

Dyspepsia has been recently considered as a biopsychosocial disorder with dysregulation of the brain-gut axis being central in origin of disease (Chua 2006). The pathophysiology of functional dyspepsia is unknown, but a number of mechanisms have been suggested. There is considerable evidence to suggest an association between disordered motility and symptom production in functional 
dyspepsia. Motor dysfunction includes antral hypomotility and delayed gastric emptying, myoelectrical abnormalities of the gastric rhythm, abnormal tone (impaired gastric accommodation), or maldistribution of food within the stomach (Stanghellini et al 2004). Although abnormal gastrointestinal motility may be the cause of the symptom production, the focus of research is shifting more toward sensory dysfunction as a primary abnormality, particularly selective visceral hypersensitivity to mechanical distension, acid hypersensitivity, or abnormal central processing of nociceptive stimuli (Timmons et al 2004). The role of Helicobacter pylori in symptom production in the absence of mucosal lesions is controversial, although $H$. pylori eradication is recommended in patients in whom no other causes of symptoms has been identified (Malfertheiner et al 2002). According to motor and/or sensory functional abnormalities causing dyspeptic symptoms, treatment options with prokinetics, serotoninergic agents, antacids, and pain modulating medications have been proposed, although proton-pump inhibitor drugs (PPIs), histamine-2 receptor antagonists, and prokinetic agents are the most commonly used (Malagelada 2001; Talley 2003a; Bytzer 2004; Delgado-Aros et al 2004).

Antidopaminergic gastrointestinal prokinetics (bromopride, clebopride, domperidone, levosulpiride, and metoclopramide) have been exploited clinically for the management of motor disorders of the upper gastrointestinal tract (Andresen and Camilleri 2006). The prokinetic effect of these drugs is mediated through the blockade of enteric (neuronal and muscular) inhibitory $\mathrm{D}_{2}$ receptors. In this respect, levosulpiride, a selective dopamine $\mathrm{D}_{2}$-receptor antagonist with prokinetic activity, is a therapeutic option in the management of functional dyspepsia on the basis of dopaminergic pathways controlling gastrointestinal motility (Distrutti et al 2002). On the other hand the serotonergic (5-HT4) component of levosulpiride may enhance its therapeutic efficacy in functional dyspepsia (Tonini et al 2004). Different studies, many of them carried out in Italy (Macarri et al 1991; Gatto et al 1992; Arienti et al 1994; Corazza et al 1996) where levosulpiride has been in the market for more than 15 years, have demonstrated the high efficacy of the drug in the control of dyspeptic symptoms and its favorable safety profile. In a review conducted to assess the clinical pharmacology, therapeutic efficacy and tolerability of levosulpiride (Corazza and Tonini 2000), the incidence of adverse events was $11 \%$ in 840 patients with dyspepsia; most of them were mild and they resulted in treatment discontinuation in only eight cases $(0.9 \%)$. The efficacy of levosulpiride and cisapride in reducing gastric emptying times with no relevant side-effects was found to be similar (Mansi et al 2000), and in a randomized, doublemasked trial, levosulpiride was at least as effective as cisapride in the treatment of dysmotility-like functional dyspepsia (Mearin et al 2004).

This study was conducted to assess the effectiveness and safety of levosulpiride in patients with dysmotility-like functional dyspepsia, including nonerosive reflux disease in conditions of daily practice.

\section{Patients and methods}

This was a prospective, open-label, observational, multinational study conducted between June 1, 2004 and November 9, 2004, at 9 sites in Latin American (Costa Rica, El Salvador, Guatemala, Honduras, Nicaragua, Panama, Paraguay, Peru, and Dominican Republic) and was globally coordinated (1 site) in Spain. The study was carried out in the primary care setting. The objective of the study was to assess the effectiveness and tolerability of levosulpiride in the treatment of patients with functional dyspepsia. Levosulpiride was administered during 4 weeks according to the conditions of use established in the product's technical form in any of the two available presentations (tablets or oral solution formulation). The duration of the study was 8 weeks (4-week treatment period and 4-week follow-up period). All patients were fully informed on the purposes and characteristics of the study and gave oral consent. Approval of the study protocol by the local ethics committees of the participating centers was not obtained because the study medication was a commercialized product and was prescribed for approved indications of use.

Patients aged 18 to 70 years of age with at least three of the following symptoms: postprandial upper abdominal fullness, postprandial pain/discomfort centered in the upper abdomen, postprandial heaviness, early satiety, nausea, pyrosis, and regurgitation were included in the study provided that symptoms had been presented at least twice a week within the preceding 3 weeks. To be included in the study, patients were required to have available the results of routine laboratory tests (blood cell count, biochemical profile, and urinalysis) and an upper gastrointestinal endoscopy carried out within the preceding 12 months. Patients with history or suspicion of organic lesion were excluded from the study as were patients undergoing abdominal surgery, patients with lactose intolerance, pregnant women or nursing mothers, and patients treated 
with drugs or medications that were known to affect gastrointestinal motility.

The study included 4 visits and its duration was of 60 days. At the baseline visit, the physician checked the eligibility criteria, and treatment with levosulpiride (Dislep ${ }^{\circledR}$, Ferrer Grupo, Barcelona, Spain) $25 \mathrm{mg}$ three times (TID) daily was begun.

Individual symptoms (postprandial pain/discomfort, postprandial fullness, postprandial bloating or abdominal distention, early satiety, nausea, vomiting, pyrosis, and regurgitation) were assessed at baseline and at 15,30, and 60 days (visits 1,2 , and 3 , respectively) after starting treatment. A computer-based questionnaire was used to assess the frequency and severity of symptoms. The frequency of symptoms was assessed according to a 4-point scale $(0=$ no symptom, $1=$ symptom present for $1-2$ days per week, 2 = 3-4 days a week, $3=5$ or more days a week, $4=$ symptoms present every day), with a total score from 0 to 10 . The severity of symptoms was scored as $0=$ no symptom, $1=$ mild and easily tolerable, $2=$ moderate or affecting normal daily activities, and $3=$ severe or preventing normal daily activities, with a total score from 0 to 6. A global symptom score that included upper abdominal pain, postprandial upper pain or discomfort, postprandial heaviness, early satiety, nausea, pyrosis, and regurgitation was also calculated.

Adverse events were monitored throughout the study. All adverse events reported by the patients or observed by the investigators were recorded, and rated by the investigator as to their relationship to the study drug (not related, possibly related, probably or definitely related) and by their severity (mild, moderate, or severe). Compliance with the prescribed dosing regimen and concomitant medication was assessed at the follow-up visits. At the final visit, patients and physicians rated the overall efficacy of treatment in a qualitative scale as excellent, good, regular, or bad.

The intent-to-treat (ITT) data set included all patients who were assessed at baseline and attended at least one follow-up visit (at 15, 30, and/or 60 days). The safety population included all patients who were assessed at baseline and received at least one dose of the study medication. Data are expressed as mean and standard deviation (SD) for quantitative variables or numbers and percentages for categorical variables. The Wilcoxon signedrank test and the Cochran Q test were used for the analysis of data. The independent effect of confounding variables (age, sex), diagnostic group, and variables statistically significant in the bivariate analysis were included in a logistic regression model, with response to treatment with levosulpiride, defined as a reduction of at least 5 points in the symptom score at the final visit compared with baseline, as the dependent variable. The SPSS 10.0 for Windows (SPSS Inc., Chicago, IL) was used for all statistical calculations. Statistical significance was defined as $p<0.05$.

\section{Results}

During the study period, treatment with levosulpiride was indicated in a total of 346 patients. Four patients, however, were excluded because inclusion criteria were not met. Therefore, 342 patients, 151 men and 191 women, with a mean (SD) age of 38.8 (12.3) years were included in the study and were treated with the study medication. There were $279(81.6 \%)$ patients with dysmotility-like functional dyspepsia and $63(18.4 \%)$ with nonerosive reflux disease. A total of $66.4 \%$ patients were treated with $75 \mathrm{mg} /$ day of levosulpiride and $33.6 \%$ with $50 \mathrm{mg} /$ day. Twenty-two patients were lost at follow-up, so that the evaluated number of patients was 341 at visit 1,331 at visit 2, and 321 at visit 3.

Baseline characteristics of the study population are summarized in Table 1. Overall, patients had suffered dyspeptic symptoms for a mean of 10.2 (10.7) months before entering the study. Duration of symptom was less than 6 months in 148 patients, between 6 and 12 months in 76 patients, and more than 12 months in the remaining 118 . Patients in whom dyspeptic symptoms had been present during less than 6 months had a mean total symptom score

Table I Baseline data of 342 patients with functional dyspepsia treated with levosulpiride

\begin{tabular}{ll}
\hline Data & $\begin{array}{l}\text { Patients } \\
\text { n (\%) }\end{array}$ \\
\hline Men/women & $15 \mathrm{I} / 19 \mathrm{I}$ \\
Age, years, mean (SD) & $38.8(12.3)$ \\
Duration of symptoms, months, mean (SD) & $10.2(10.7)$ \\
$<6$ months, $\mathrm{n}(\%)$ & $148(43.3)$ \\
$6-12$ months & $76(22.2)$ \\
$>12$ months & $118(34.5)$ \\
Alcohol (mean 22.5g ethanol/day), $\mathrm{n}(\%)$ & $77(22.5)$ \\
Current smokers, $\mathrm{n}(\%)$ & $25(7.3)$ \\
Concomitant medication & \\
Prokinetic drugs & $88(25.7)$ \\
Proton pump inhibitors & $47(13.6)$ \\
Antidopaminergic prokinetic agents & $4 \mathrm{I}(1 \mathrm{I} .8)$ \\
Anti- $\mathrm{H}_{2}$ agents & $2 \mathrm{I}(6.1)$ \\
Antacids & $30(8.7)$ \\
Antispasmolytic drugs & $20(5.8)$ \\
Digestive enzymes & $4(1.2)$ \\
\hline
\end{tabular}

Abbreviations: SD, standard deviation. 
of 6.2 compared with 6.7 in patients with longer evolution of functional dyspepsia. On the other hand, although patients were not randomly selected for the two dosing scheduled arms, there was a trend to prescribe the daily dose of levosulpiride of $50 \mathrm{mg}$ twice (BID) daily in patients with shorter duration of symptoms and the daily dose of $75 \mathrm{mg}$ TID in patients with longer duration of symptoms.

Endoscopic abnormalities were recorded in $23.4 \%$ of patients. However, as expected, the number of patients with endoscopic abnormalities was significantly higher among patients with nonerosive reflux disease than in those with dysmotility-like dyspepsia (33.3\% vs $13.3 \%$, p<0.01).

Alcohol consumption was recorded in $22.5 \%$ of patients (mean 22.2 [8.7 g] ethanol per day) and current smoking in $7.3 \%$. Other underlying conditions, such as diabetes, hypertension, previous surgery unrelated to the current diagnosis, were found in less than $1 \%$ of patients. With regard to history of alcohol consumption and cigarette smoking, there were no significant differences according to diagnoses of dysmotility-like dyspepsia or nonerosive reflux disease, but a significantly higher percentage of patients with duration of dyspeptic symptoms $>6$ or 12 months reported alcohol consumption (34.8\%) and smoking
$(8.2 \%)$ compared with patients with duration of dyspeptic symptoms $<6$ months $(8.4 \%$ and $1.4 \%$, respectively) $(\mathrm{p}<$ $0.05)$. The mean systolic blood pressure was 119.7 (12.2) $\mathrm{mm} \mathrm{Hg}$, diastolic blood pressure 74.7 (8.1) $\mathrm{mm} \mathrm{Hg}$, and heart rate $77.6(7.1)$ beats/min.

\section{Effectiveness}

At the 15-day visit, a decrease greater than 50\% in the total symptom score was observed. The total symptom score decreased significantly ( $\mathrm{p}<0.001)$ from a mean (SD) of 6.5 (2.5) at baseline to $3.1(2.0)$ at visit $1,1.4$ (1.6) at visit 2, and $1.2(1.7)$ at visit 3 (Figure 1). The frequency and intensity of individual symptoms showed a statistically significant decrease $(\mathrm{p}<0.001)$ at all visits compared with baseline. At the 30-day visit, all symptoms had almost disappeared, a trend that was maintained until the last visit (Table 2). Statistically significant differences regarding the reduction of individual symptoms and total symptom score between the groups of patients with dysmotility-like dyspepsia and nonerosive reflux disease were not found. The percentages of patients rating nausea, pyrosis, regurgitation, and postprandial upper abdominal fullness as

Table 2 Comparison of individual symptoms at baseline and at the end of the study in 342 patients with functional dyspepsia treated with levosulpiride.

\begin{tabular}{|c|c|c|c|c|c|c|c|c|c|}
\hline \multirow[t]{2}{*}{ Symptoms } & \multicolumn{3}{|c|}{ Intensity of symptoms } & \multicolumn{6}{|c|}{ Frequency of symptoms } \\
\hline & Absent & Mild & Moderate & Severe & Absent & I-2 days & 3-4 days & $\geq 5$ days & Daily \\
\hline \multicolumn{10}{|c|}{ Abdominal distention } \\
\hline Baseline & $46(13.5)$ & $54(15.8)$ & $202(59.1)$ & 38 (II.I) & $46(13.6)$ & 54 (I5.9) & $60(17.7)$ & $82(24.2)$ & $97(28.6)$ \\
\hline Visit 3 (60 days) & $213(66.4)$ & $93(29.0)$ & $14(4.4)$ & $\mathrm{I}(0.3)$ & $213(66.4)$ & $52(16.2)$ & $22(6.9)$ & $10(3.1)$ & $24(7.5)$ \\
\hline \multirow{2}{*}{\multicolumn{10}{|c|}{$\begin{array}{l}\text { Upper abdominal pain/ } \\
\text { discomfort }\end{array}$}} \\
\hline & & & & & & & & & \\
\hline Baseline & $57(16.8)$ & $126(37.1)$ & |3| (38.5) & $26(7.6)$ & $57(16.8)$ & $59(17.4)$ & $74(21.8)$ & $62(18.2)$ & $88(25.9)$ \\
\hline Visit 3 (60 days) & $228(71.0)$ & $88(27.4)$ & $4(1.2)$ & I (0.3) & $228(71.0)$ & $33(10.3)$ & $13(4.0)$ & $10(3.1)$ & $37(11.5)$ \\
\hline \multicolumn{10}{|l|}{ Postprandial fullness } \\
\hline Baseline & $51(14.9)$ & 7I (20.8) & $185(54.1)$ & $33(9.6)$ & $5 I(15.0)$ & $4 I(12.1)$ & $76(22.4)$ & 78 (22.9) & $94(27.6)$ \\
\hline Visit 3 (60 days) & $240(74.8)$ & $77(24.0)$ & $4(1.2)$ & 0 & $240(74.8)$ & $45(14.0)$ & $22(6.9)$ & $4(1.2)$ & $10(3.1)$ \\
\hline \multicolumn{10}{|l|}{ Early satiety } \\
\hline Baseline & $104(30.7)$ & $129(38.1)$ & $78(23.0)$ & $28(8.3)$ & $104(30.8)$ & $44(13.0)$ & 84 (24.9) & $4 I(12.1)$ & $65(19.2)$ \\
\hline Visit 3 (60 days) & $283(88.7)$ & $33(10.3)$ & $2(0.6)$ & I $(0.3)$ & $283(89.0)$ & $22(6.9)$ & $6(1.9)$ & $3(0.9)$ & $4(1.3)$ \\
\hline \multicolumn{10}{|l|}{ Nausea (related with } \\
\hline \multicolumn{10}{|l|}{ food ingestion) } \\
\hline Baseline & $182(53.5)$ & 95 (27.9) & $43(12.6)$ & $20(5.9)$ & I $82(53.5)$ & $64(18.8)$ & $36(10.6)$ & $20(5.9)$ & $38(11.2)$ \\
\hline Visit 3 (60 days) & $310(96.9)$ & $10(3.1)$ & 0 & 0 & $310(96.9)$ & $8(1.5)$ & 0 & 0 & $2(0.6)$ \\
\hline \multicolumn{10}{|l|}{ Pyrosis } \\
\hline Baseline & $218(63.9)$ & $67(19.6)$ & $50(14.7)$ & $6(1.8)$ & $218(63.9)$ & $43(12.6)$ & 38 (II.I) & $13(3.8)$ & $29(8.5)$ \\
\hline Visit 3 (60 days) & $296(92.2)$ & $24(7.5)$ & 0 & $\mathrm{I}(0.3)$ & $296(92.2)$ & $13(4.0)$ & $\mathrm{I}(0.3)$ & $2(0.6)$ & $9(2.8)$ \\
\hline \multicolumn{10}{|l|}{ Regurgitation } \\
\hline Baseline & $283(83.0)$ & $34(10.0)$ & $21(6.2)$ & $3(0.9)$ & $283(83.0)$ & $26(7.6)$ & $12(3.5)$ & $2(0.6)$ & $18(5.3)$ \\
\hline Visit 3 (60 days) & $313(97.5)$ & $8(2.5)$ & 0 & 0 & $313(97.5)$ & $2(0.6)$ & I (0.3) & 0 & $5(1.6)$ \\
\hline
\end{tabular}

Note: $p=0.001$ for the comparisons of intensity and frequency of symptoms between baseline and visit 3 . 
severe or moderate had decreased to practically $0 \%$ at the end of the study (Figures 2 to 5).

Concomitant medication in all visits and diagnostic groups was lower than $1 \%$. Compliance with treatment was higher than $96 \%$ in all cases $(98.8 \%$ at the 15 -day visit and $96.9 \%$ at the final visit). The effectiveness of treatment was

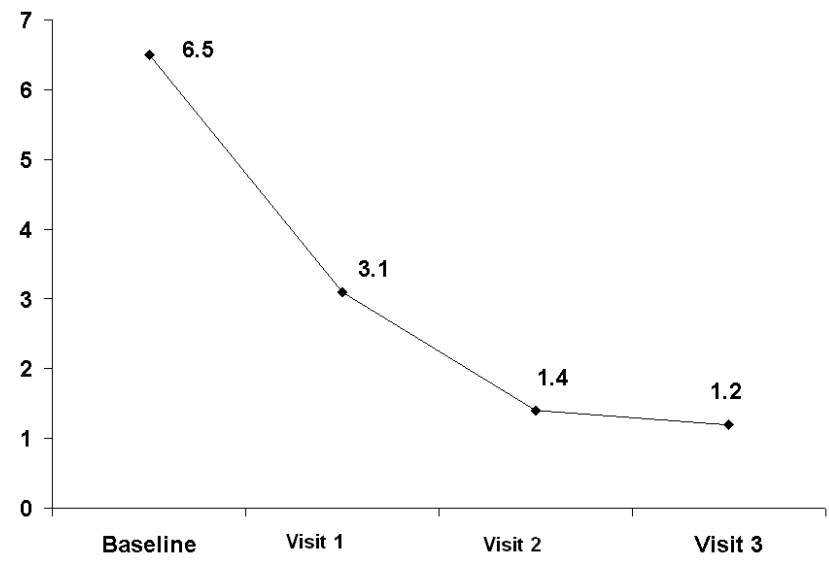

Figure I Decrease of total symptom score during the study.

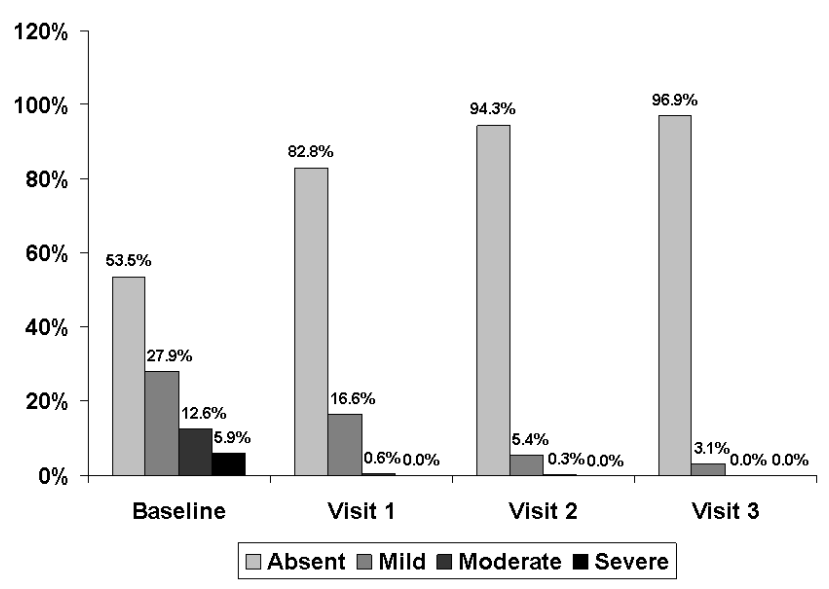

Figure 2 Changes in the severity of nausea throughout the study.

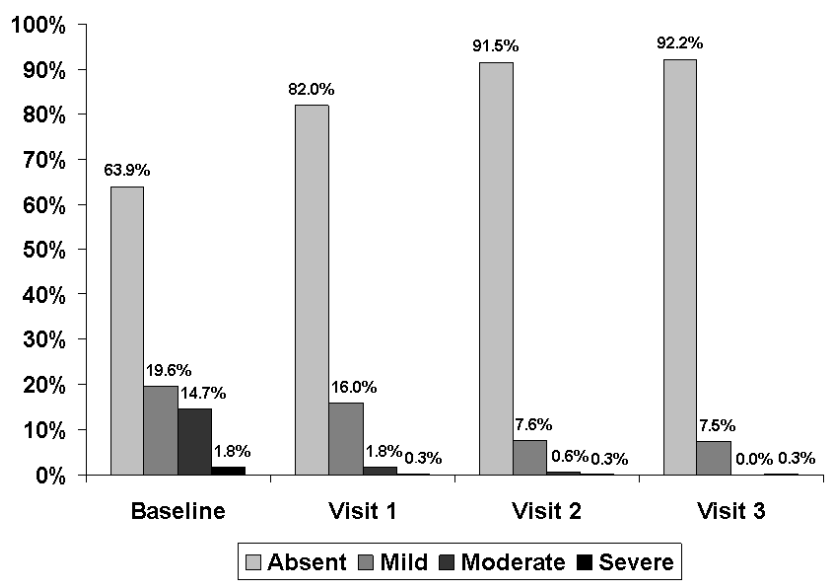

Figure 3 Changes in the severity of pyrosis throughout the study.

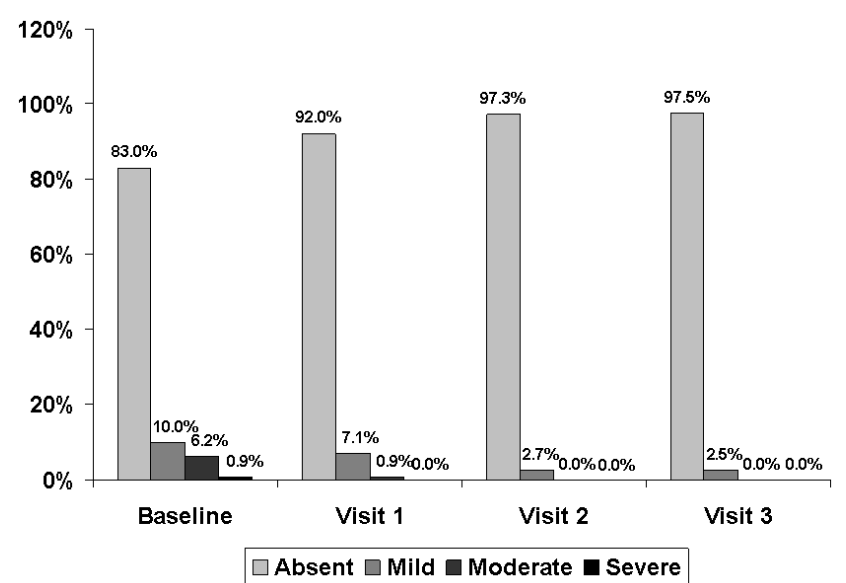

Figure 4 Changes in the severity of regurgitation throughout the study.

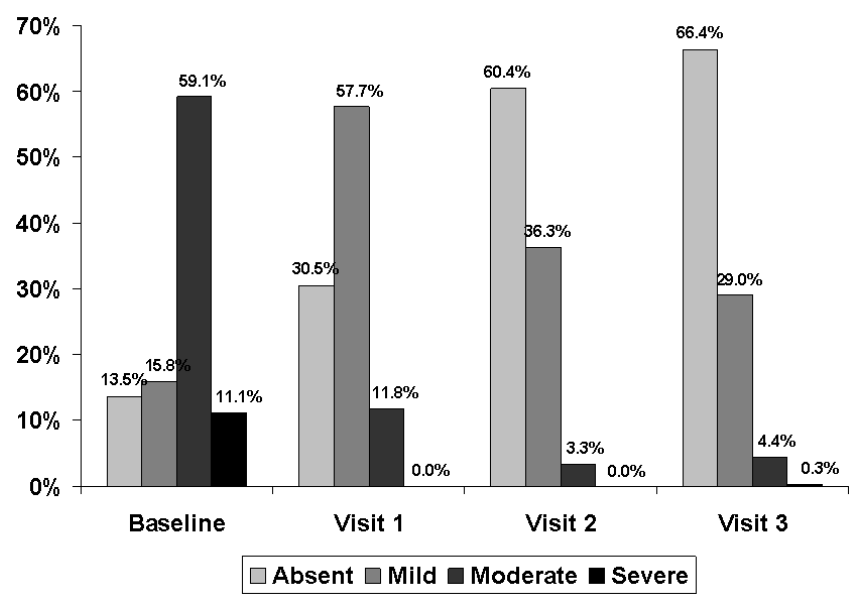

Figure 5 Changes in the severity of abdominal fullness throughout the study.

considered excellent or good by $92.5 \%$ of physicians and $90.3 \%$ of patients at the 30-day visit, and by $93.4 \%$ of physicians and $91 \%$ of patients at the 60 -day visit.

In the multivariate analysis, response to treatment with levosulpiride was 4.13 higher in smokers compared with non-smokers, 0.53 greater in patients with nonerosive reflux disease compared with patients with dysmotility-like dyspepsia, and 0.17 times higher in patients with both diagnoses compared with patients with a single diagnosis. Doses of levosulpiride were not selected as predictors of response.

\section{Safety}

Treatment with levosulpiride was well tolerated and only 40 adverse events were recorded (galactorrhea 26.7\%, somnolence $17.8 \%$, fatigue $11.1 \%$, headache 11.5 ) and no patient had to abandon the study due to side effects. Most side effects were considered possibly or probably related to the study medication as the events recorded were those reported in the product's technical form. A total of $66.7 \%$ 
of side effects occurred during the first 15 days of treatment with levosulpiride. As shown in Figure 6, the intensity of adverse events was higher at the first visit and the few adverse events still present at follow-up were of mild intensity.

\section{Discussion}

This descriptive, observational, multinational study in which levosulpiride was administered to patients with functional dyspepsia according to indications of use in daily practice confirms the effectiveness and safety of this prokinetic agent, which is in accordance with previous data reported in the literature. On the other hand, trials in functional dyspepsia report placebo response rates of $30 \%$ to $40 \%$ (Talley et al 2006). This study has several important limitations. The principal limitations were the open-label design and the absence of a comparison group. Another limitation was that the study was based on criteria of Rome II consensus report (Talley et al 1999). The Rome III committee recommends the term "dyspepsia" be restricted to patients with epigastric pain or burning, postprandial fullness, or early satiation (Tack et al 2006). The committee further opined that the term "functional dyspepsia" has limited utility and, based on factor analysis data, suggested that there are specific syndromes (epigastric pain syndromes and postprandial distress syndrome) that can be identified and may better characterize those patients formally labeled as having functional dyspepsia. This new classification remains to be prospectively tested, and, at this stage, abandonment of the term "functional dyspepsia" seems premature.

Although these limitations should be taken into account when interpreting the results of this study, the present findings, however, add evidence of the efficacy of levosulpiride in different geographical settings mostly Latin American countries, showing that differences in lifestyle and behavioral and environmental factors had no influence on the distinct pathophysiological abnormalities present in subgroups of patients with this heterogeneous disorder. Levosulpiride has demonstrated an excellent effectiveness for the control of symptoms of both functional dyspepsia and nonerosive reflux disease as shown by significant decreases in the total symptom score and in the percentage of individual clinical symptoms, including symptoms that are less characteristic of the disease.

Levosulpiride was well tolerated and all side effects were in accordance with those reported in previous studies and coincided with the descriptions in the package insert of the drug. The prokinetic agent cisapride has been a well-

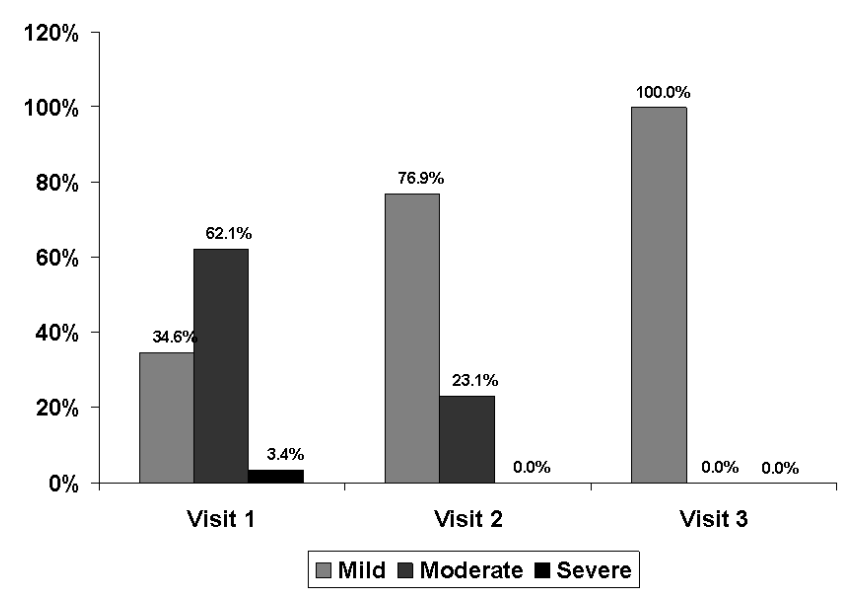

Figure $\mathbf{6}$ Intensity of adverse events at the follow-up visits.

evaluated form of pharmacological treatment for patients with functional dyspepsia, but serious cardiovascular effects with the use of this drug have been reported, which caused removal of the drug from the US market in 2000. A recent systematic review of management strategies (combinations of initial investigation and empirical treatments) for dyspeptic patients (Delaney et al 2005) concludes that PPIs are effective in the treatment of dyspepsia in those trials which may not adequately exclude patients with gastroesophageal reflux disease. The relative efficacy of histamine H2-receptor antagonists (H2RAs) and PPIs is uncertain. Early investigation by endoscopy or $H$. pylori testing may benefit some patients with dyspepsia but is not cost effective as part of an overall management strategy. The prokinetic effect of levosulpiride is mediated through the blockade of enteric (neuronal and muscular) inhibitory $\mathrm{D}_{2}$ receptors, and the ability to interact with $5-\mathrm{HT}_{4}$ receptors. The serotonergic $\left(5-\mathrm{HT}_{4}\right)$ component of antidopaminergic prokinetics enhances their therapeutic efficacy in gastrointestinal disorders, such as functional dyspepsia and diabetic gastroparesis (Mansi et al 1995; Tonini et al 2004). The antagonism of central $\mathrm{D}_{2}$ receptors may lead to both therapeutic (eg, antiemetic effect due to $\mathrm{D}_{2}$ receptor blockade in the area postrema) and adverse (including hyperprolactinemia and extrapyramidal dystonic reactions) effects. Hyperprolactinemia is a side effect occurring with all antidopaminergic prokinetics. In a randomized, doublemasked trial (Mearin et al 2004) in which the effects of the effects of 8 weeks of treatment with either levosulpiride $25 \mathrm{mg}$ TID ( $\mathrm{n}=69)$ or cisapride $10 \mathrm{mg}$ TID $(\mathrm{n}=71)$ were compared. Both levosulpiride and cisapride improved dyspeptic symptoms and decreased total symptom score (79.9\% and $71.3 \%$, respectively); no significant statistical 
difference between treatments was found $(\mathrm{p}=0.07$ for total symptom score). However, significantly more $(p=0.03)$ patients treated with cisapride had to abandon the trial because of side effects.

The present data obtained in a large group of adult patients with functional dyspepsia diagnosed and treated by their physicians in daily practice confirm the effectiveness and safety of a 4-week treatment regimen with levosulpiride for the relief of dyspeptic symptoms. Further studies are needed to examine our findings of better responses in smokers compared with nonsmokers as well as in patients with nonerosive reflux disease compared with dysmotilitylike functional dyspepsia.

\section{Acknowledgments}

We thank Marta Pulido, MD, for editing the manuscript and editorial assistance.

\section{References}

Andresen V, Camilleri M. 2006. Challenges in drug development for functional gastrointestinal disorders. Part I: functional dyspepsia. Neurogastroenterol Motil, 18:346-53.

Arienti V, Corazza GR, Sorge M, et al. 1994. The effects of levosulpiride on gastric and gall-bladder emptying in functional dyspepsia. Aliment Pharmacol Ther, 8:631-8.

Bodger K, Eastwood PG, Manning SI, et al. 2000. Dyspepsia workload in urban general practice and implications of the British Society of Gastroenterology Dyspepsia guidelines (1996). Aliment Pharmacol Ther, 14:413-20.

Bytzer P. 2004. Diagnostic approach to dyspepsia. Best Pract Res Clin Gastroenterol, 18:681-93.

Caballero Plasencia AM, Sofos Kontoyannis S, Valenzuela Barranco M, et al. 2000. Epidemiology of dyspepsia in a random Mediterranean population. Prevalence of Helicobacter pylori infection. Rev Esp Enferm Dig, 92:781-92.

Chua AS. Reassessment of functional dyspepsia: a topic review. 2006. World J Gastroenterol, 12:2656-9.

Corazza GR, Biagi F, Albano O, et al. 1996. Levosulpiride in functional dyspepsia: a multicentric, double-blind, controlled trial. Ital $J$ Gastroenterol, 28:317-23.

Corazza GR, Tonini M. 2000. Levosulpiride for dyspepsia and emesis: a review of its pharmacology, efficacy and tolerability. Clin Drug Invest, 19:151-62.

Delaney B, Ford A, Forman D, et al. 2005. Initial management strategies for dyspepsia Cochrane Database Syst Rev, 19(4):CD001961.

Delgado-Aros S, Cremonini F, Talley NJ. 2004. Treatment of functional dyspepsia. Curr Treat Options Gastroenterol, 7:121-31.

Distrutti E, Fiorucci S, Hauer SK, et al. 2002. Effect of acute and chronic levosulpiride administration on gastric tone and perception in functional dyspepsia. Aliment Pharmacol Ther, 16:613-22.
Gatto G, Ricca T, Randazzo M. 1992. Clinical efficacy and safety of Levosulpiride and domperidone in the management of chronic functional dyspepsia: a double blind, randomized clinical trial. Curr Ther Res, 51:715-22.

Heikkinen M, Pikkarainen P, Takala J, et al. 1996. General practitioners' approach to dyspepsia. Survey of consultation frequencies, treatment, and investigations. Scand J Gastroenterol, 31:648-53.

Jones R, Lydeard S. 1989. Prevalence of symptoms of dyspepsia in the community. BMJ, 298:30-2.

Jones R, Lydeard S. 1992. Dyspepsia in the community: a follow-up study. Br J Clin Pract, 46:95-7.

Macarri G, Biasi L, Brunelli E. 1991. L-sulpiride contro metoclopramide nella dispepsia funzionale: studio randomizzato in doppio cieco. Minerva Med, 82:1-4.

Maconi G, Tosetti C, Stanghellini V, et al. 2002. Dyspeptic symptoms in primary care. An observational study in general practice. Eur $J$ Gastroenterol Hepatol, 14:985-90.

Malagelada JR. 2001. Review article: the continuing dilemma of dyspepsia Aliment Pharmacol Ther, 15(Suppl 1):6-9.

Malfertheiner P, Megraud F, O'Morain C, et al. 2002. Current concepts in the management of Helicobacter pylori infection - the Maastricht 22000 Consensus Report. Aliment Pharmacol Ther, 16:167-80.

Mansi C, Borro P, Giacomini M, et al. 2000. Comparative effects of levosulpiride and cisapride on gastric emptying and symptoms in patients with functional dyspepsia and gastroparesis. Aliment Pharmacol Ther, 14:561-9.

Mansi C, Savarino V, Vigneri S, et al. 1995. Gastrokinetic effects of levosulpiride in dyspeptic patients with diabetic gastroparesis. $\mathrm{Am} \mathrm{J}$ Gastroenterol, 90:1989-93.

Mearin F, Rodrigo L, Perez-Mota A, et al. 2004. Levosulpiride and cisapride in the treatment of dysmotility-like functional dyspepsia: a randomized, double-masked trial. Clin Gastroenterol Hepatol, 2:301-8.

Meineche-Schmidt V, Krag E. 1998. Dyspepsia in general practice in Denmark. A 1-year analysis of consulters in general practice. Scand $J$ Prim Health Care, 16:216-21.

Stanghellini V, De Giorgio R, Barbara G, et al. 2004. Delayed gastric emptying in functional dyspepsia. Curr Treat Options Gastroenterol, 7:259-64.

Tack J, Talley NJ, Camilleri M, et al. 2006. Functional gstroduodenal disorders. Gastroenterology, 130:1466-79.

Talley NJ, Stanghellini V, Heading RC, et al. 1999. Functional gastroduodenal disorders. Gut, 45(Suppl 2):II37-42.

Talley NJ. 2003a. Dyspepsia. Gastroenterology, 125:1219-26.

Talley NJ. 2003b.Update on the role of drug therapy in non-ulcer dyspepsia. Rev Gastroenterol Disord, 3:25-30.

Talley NJ, Locke GR, Lahr BD, et al. 2006. Predictors of the placebo response in functional dyspepsia. Aliment Pharmacol Ther, 23:92336.

Timmons S, Liston R, Moriarty KJ. 2004. Functional dyspepsia: motor abnormalities, sensory dysfunction, and therapeutic options. Am J Gastroentrol, 99:739-49.

Tonini M, Cipollina L, Poluzzi E, et al. 2004. Clinical implications of enteric and central D2 receptor blockade by antidopaminergic gastrointestinal prokinetics. Aliment Pharmacol Ther, 19:379. doi 10.1111/j.1365-2036.2004.01867.x

Van Bommel MJ, Numans ME, de Wit NJ, et al. 2001. Consultations and referrals for dyspepsia in general practice - a one year database survey. Postgrad Med J, 77:514-18. 
